\title{
Commentary: Of mice and Marfan
}

\author{
Darrell $\mathrm{Wu}, \mathrm{MD}$, and Shuab Omer, MD
}

\footnotetext{
From the Division of Cardiothoracic Surgery, Baylor College of Medicine, Michael E. DeBakey VA Medical Center, Houston, Tex.

Disclosures: Authors have nothing to disclose with regard to commercial support.

Received for publication May 19, 2019; accepted for publication May 21, 2019; available ahead of print June 21, 2019.

Address for reprints: Shuab Omer, MD, Division of Cardiothoracic Surgery, Baylor College of Medicine, Michael

E. DeBakey VA Medical Center, 2002 Holcombe Blvd, Houston, TX 77030 (E-mail: shuab.omer@bcm.edu). J Thorac Cardiovasc Surg 2020;159:1727-8

$0022-5223 / \$ 36.00$

Copyright (C) 2019 by The American Association for Thoracic Surgery

https://doi.org/10.1016/j.jtcvs.2019.05.044
}

Hereditary aortic pathology is typically characterized by destructive extracellular matrix remodeling. For Marfan syndrome (MFS), an autosomal dominant connective tissue disorder, the principal mutation in the fibrillin gene (FBN1) on chromosome 15 leads to dysregulated elastic fiber homeostasis with variable phenotypic expression but highly penetrant thoracic aortic disease. Murine models that have been developed to recapitulate the dominant negative effects of $F B N 1$ deletion have shown a complex interplay between angiotensin II (ANGII) and transforming growth factor- $\beta$ (TGF- $\beta$ ) signaling. Although these murine models have identified promising targets, translation to clinical use has not materialized, suggesting that further studies are needed to elucidate the mechanisms behind MFS-induced aortic disease and cardiomyopathy. The FbnC1039G/+ mouse has been widely used to study MFS, but this model is hampered by the length of time (months) it takes for manifestations of cardiovascular disease. In this issue of The Journal of Thoracic and Cardiovascular Surgery, Gensicke and colleagues ${ }^{1}$ have attempted to validate their accelerated (weeks) murine model of MFS by examining well-established signaling pathways in MFS.

Gensicke and colleagues ${ }^{1}$ used FbnC1039G/+ heterozygous mice on a B6.129 background supplemented with ANGII infusion to study the downstream effects in canonical (Smad 2) and noncanonical (ERK and P38) pathways. They found that RNA and protein expressions of downstream signaling in both pathways were exaggerated relative to control in cardiac and aortic tissue of MFS-model mice infused with ANGII. Furthermore, with the same model in an earlier study, this group found accelerated thoracic aortic disease with aneurysm formation in the course of 14 days and an almost $40 \%$ mortality. $^{2}$ In contrast, other murine models without ANGII infusion can take months for disease development. ${ }^{3}$ Although this study does provide an accelerated murine MFS model, there are 3 main points that bear mentioning when considering this it. First, while the control mice were derived

\section{References}

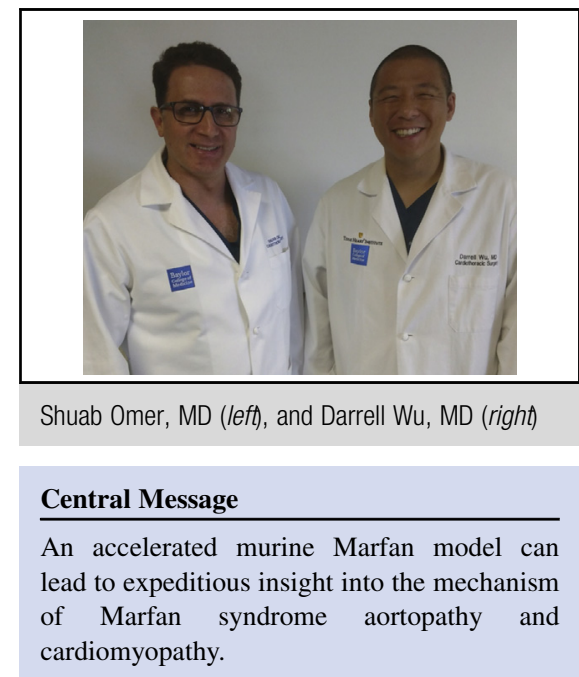

See Article page 1719.

from the embryonic cell line 129 /sv, the strain was backcrossed with C57BL/6 mice for more than 9 generations; however, the phenotypic expression of aortopathy for B6.129 is different than for C57BL/6 background mice with $F B N$ mutation with B6.129 mice having aortopathy develop earlier than C57BL/6 mice. ${ }^{4}$ Second, the dose of ANGII is many times higher than in sporadic murine models of aortic disease. 5 This raises the question of whether the cause of aortopathy from supratherapeutic doses of ANGII is indicative of MFS or is even clinically relevant. Third, although their results indicate that there is overexpression of TGF- $\beta$ downstream signaling pathways, it remains unclear whether the phosphorylated or activated form in both canonical and noncanonical pathways truly drives this process, since there was no difference between ANGII-infused MFS mice and MFS mice. Furthermore, the differential role of TGF- $\beta$ in murine MFS aortopathy ${ }^{6}$ and the crosstalk between ANGII and TGF- $\beta$ are complex and unclear. ${ }^{7}$

Nonetheless, establishment of a consistent, timesensitive murine model that reproduces the cardiovascular manifestations of MFS allows rapid investigation into the molecular mechanisms of MFS. This investigation can lead to development of new therapeutic targets.

1. Gensicke NM, Cavanaugh NB, Andersen ND, Huang T, Qian L, Dyle MC, et al Accelerated Marfan syndrome model recapitulates established signaling pathways. J Thorac Cardiovasc Surg. 2020;159:1719-26. 
2. Cavanaugh NB, Qian L, Westergaard NM, Kutschke WJ, Born EJ, Turek JW. A novel murine model of Marfan syndrome accelerates aortopathy and cardiomyopathy. Ann Thorac Surg. 2017;104:657-65.

3. Habashi JP, Judge DP, Holm TM, Cohn RD, Loeys BL, Cooper TK, et al. Losartan, an AT1 antagonist, prevents aortic aneurysm in a mouse model of Marfans syndrome. Science. 2006;312:117-21.

4. Lima BL, Santos EJ, Fernandes GR, Merkel C, Mello MR, Gomes JP, et al. A new mouse model for Marfan syndrome presents phenotypic variability associated with the genetic background and overall levels of Fbn1 expression. PLos One. 2010;5:e14136.
5. Daugherty A, Manning MW, Cassis LA. Angiotensin II promotes atherosclerotic lesions and aneurysms in apolipoprotein E-deficient mice. J Clin Invest. 2000; 105:1605-12.

6. Wei H, Hu JH, Angelov SN, Fox K, Yan J, Enstrom R, et al. Aortopathy in a mouse model of Marfan syndrome is not mediated by altered transforming growth factor B signaling. J Am Heart Assoc. 2017;6.

7. Cook JR, Clayton NP, Carta L, Galatioto J, Chiu E, Smaldone S, et al. Dimorphic effects of transforming growth factor- $\beta$ signaling during aortic aneurysm progression in mice suggests a combinatorial therapy for Marfan syndrome. Arterioscler Thromb Vasc Biol. 2015;35:911-7. 